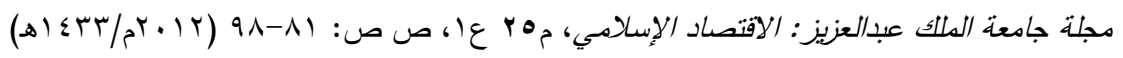
DOI: 10.4197 / Islec. 25-1.3

\title{
الاقتصاد الإسلامي بين التوجيه والتشريع
}

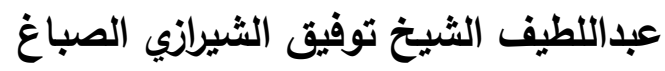

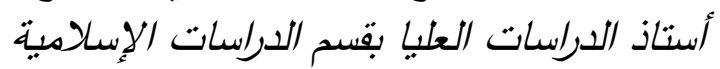 \\ كلبة الآداب - جامعة الملك عبدالعزيز - جدة العات العالة \\ المملكة العربية السعودية المعابة
}

الستخلص. تبين هذه المحاضرة أهم خصائص النظام الاقتصادي في

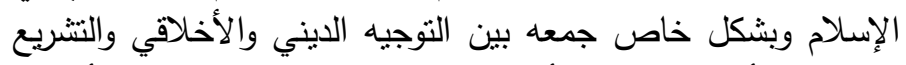

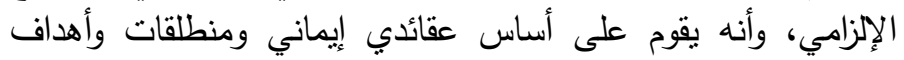

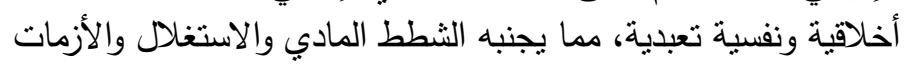

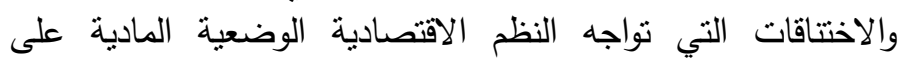

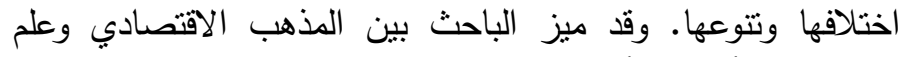

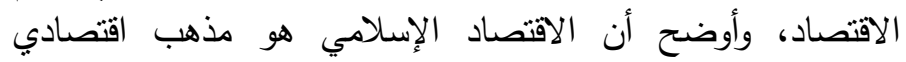
منكامل وليس علم اقتصاد. كما أكد الباحث على الإنى أن الأن الاقتصاد

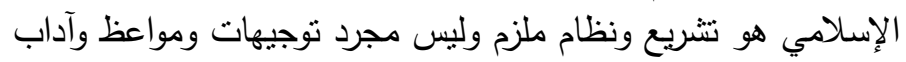

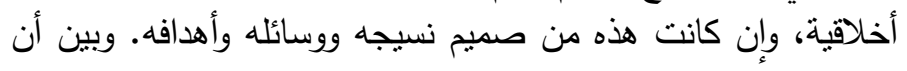

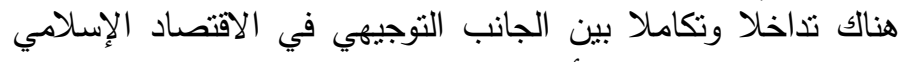

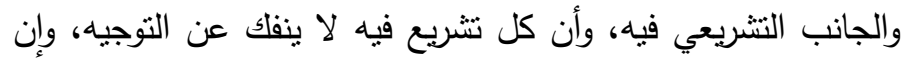

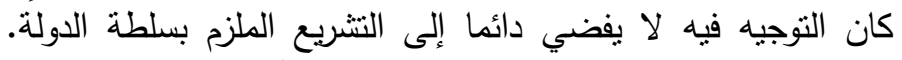

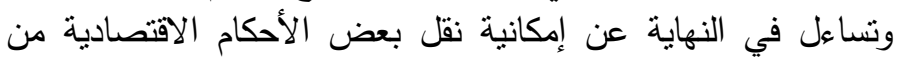

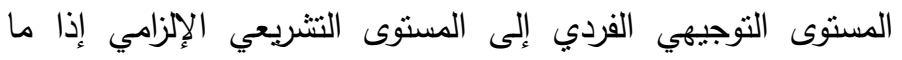

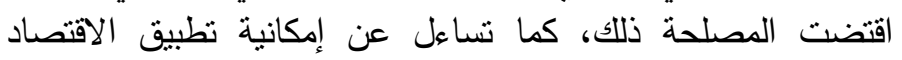
الإسلامي في مجتمع غير إسلامي؟ 
الحمدله الذي أنزل الكتاب ولم يجعل له عوجا، والصلاة والسلام على سيدنا محمد إمام الهدى والتقوى، الذي جعله ربه على شربعة من الأمر ليتبعها هو وأصحابه وأتباعه دن بعدهم، ولا يتبعوا أهواء الذين لا يعلمون، صاحب الدين الخاتم

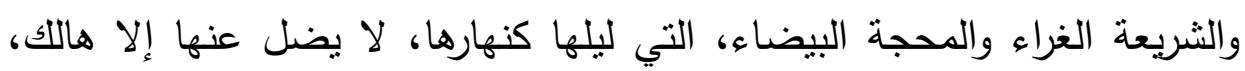
وعلى آله وصحبه وأتباعهم وناصريهم إلى يوم الدين، وبعد.

فكم أنا شاكر ومقدر لأخي سعادة الأستاذ الدكتور إبراهيم أبوالعلا وللإخوة

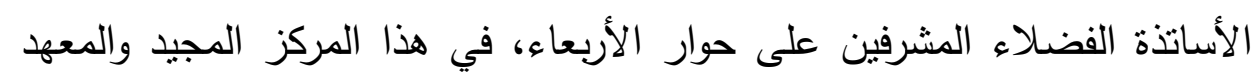
العتيد، دعوتهم الأخوية الودودة التي تتبئ عن ثقتهم بأخيهم وحسن ظنهم به، وما أنا إلا صاحب بضاعة مزجاة وخواطر شاردة ومعارف قديمة تجاوزها الزمن بدراسات رصينة، وأبحاث طريفة، وأفكار تتفتق عنها أذهان حادة، وأنظار نافذة. وأصحاب منهجية علمية مسددة.

أحب أولاً أن أثيد بهذه الحوارات واللقاءات العلمية المفيدة والمباركة

التي أصبحت زادًا وموردًا للكثيرين، وأثيد باستمرارها والحرص على إقامتها حتى أضحت مثنلاً يحتذى في كثير من الكليات والأقسام العلمية في جامعتتا الحبيية الناهضة. وأحب أن أذكر بالتحية والتجلة والتقدير أخانا العزيز الباحث الناقد الأستاذ الدكتور رفيق يونس المصري الذي سنّ هذه السنة الحسنة في هذا المركز المبارك، فأسأل الله تعالى أن يكتب له أجرها وأجر من عمل بها وسار على هلى لهن منوالها ما بقي هذا المركز يعطي ويشع!

\section{() قصتي مع الاقتصاد الإسلامي}

وأحب أن أبين لكم أنني لست متخصصيًا تخصصًا دقيقًا في الفقه الإسلامي، وإن كنت من هواته، ولا في الاقتصاد الإسلامي وإن كنت من شداته، وأثنعر ، أحيانًا، عندما أتحدث أمامكم أو عندما أعلق على ندوة أو مداخلة، أنني 
كبائع الماء في حارة السقائين، أو كجالب التمر إلى هجر، ولكن الهواية لها تكاليفها، والثَدْرُ لله مستلزماته وموجباته، فاقبلوا مني إذن جهد المقل.

وترجع قصتي مع الفقه ومع الاقتصاد ومع الاقتصاد الإسلامي، إلى ما قبل خمسة وخمسين عامًا، عندما كنا ندرس الفقه وفقه المعاماتات في المدرسة الخسروية بحلب من عام 90 (م وحتى عام 90 (م، ثم انتقلنا لندرس في كلية الشريعة بجامعة دمشق عام 90V ام وحتى الو ام، حيث كان أساتنتا الموقرون، رحمه الله تعالى، بدرسون لنا فقه المعاملات في كتاب الهداية للمرغيناني، وفي تحفة الفقهاء للسمرقندي وفي شرح البدائع للكاساني، لكن الذي حبينا في الفقه ونظرياته حينذاك هو كتاب المدخل الفقهي العام لأستاذنا العلامة الثيخ مصطفى الزرقا، رحمه الله تعالى، بما احتوى عليه من تاريخ التشريع ونظريات الحق والعقد والأهلية والموئيدات الشرعية ثم القواعد الفقهية وشرحها. وكانت المحاضرات التي كان يلقيها علينا أستاذنا النابغة الثيخ المفكر محمد المبارلك، رحمه الله تعالى، عن عقائد الإسلام وعباداته وأخلاقه ونظمه المختلفة تحت عنوان واحد، ابتكره هو نفسه، وهو " نظام الإسلام "، الذي كان اسم مادة أساسية في السنة الأولى من كلية الثربعة، تثير فينا الكثير من الحماس والتقة بعظمة الإسلام وتكامل أحكامه وجوانبه العقدية والأخلاقية والتشريعية لنقده للناس على أنه نظام كامل متميز في مقابل الإيديولوجيات الأخرى، كالثيوعية والاشتراكية والرأسمالية والقومية والمادية، التي كانت تعج بها الساحة الفكرية والسياسية في سورية في ذلك الوقت، في غمرة صراع فكري عنيف كانت بلادنا تمر فيه وتصلينا بناره، ولكنه مع ذلك كان ينضجنا أيضًا، ويدفعنا إلى مزيد من المعرفة والاطلاع.

وكان جانب مهم من جوانب (نظام الإسلام) يثثر إعجابنا وحماسنا في معركتنا مع الاشتراكية والثيوعية والرأسمالية، ألا وهو الاقتصاد الإسلامي الذي 
أصبح فيما بعد أحد سلسلة كتب نظام الإسلام للأستاذ محمد المبارك رحمه الله

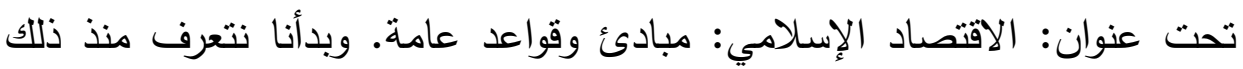

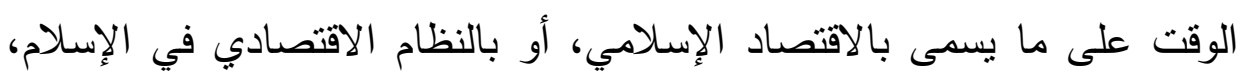
وعلى منطلقاته وأهدافه وأحكامه وتوجيهاته. وقد قوّى جانب دراسة الاقتصاد لدينا في ذلك الوقت أن مادة كانت تدرس

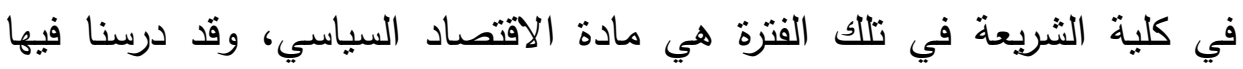
كتاب: مبادئ الاقتصاد السياسي للأستاذ الدكتور أحمد السمان، رحمه الله، الذي لفي

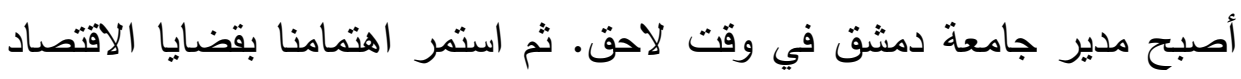

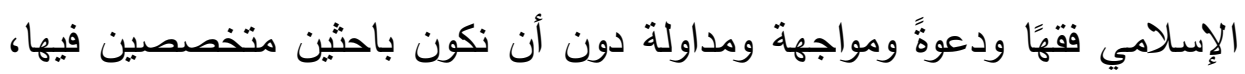

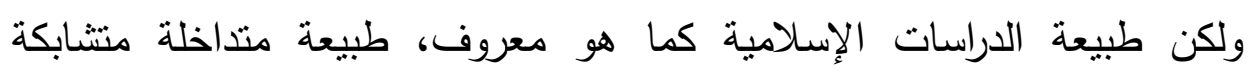

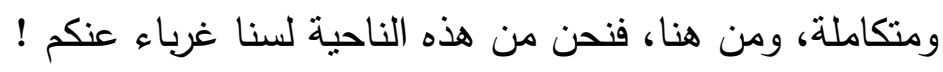

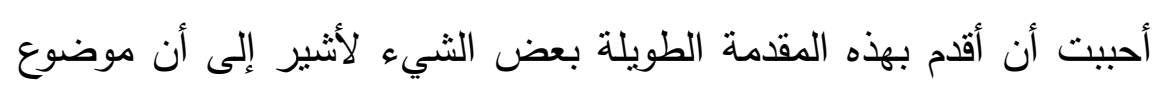

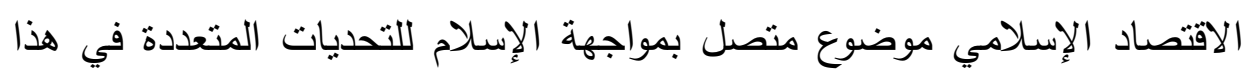

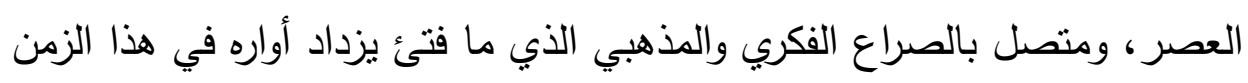

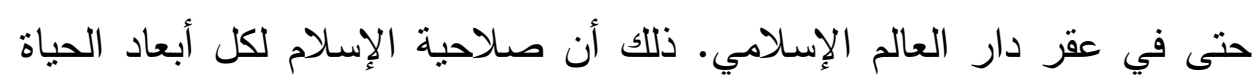

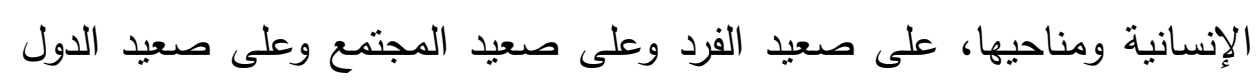

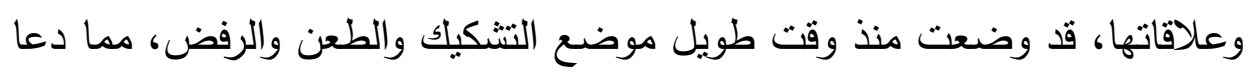

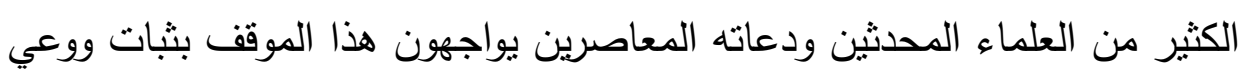

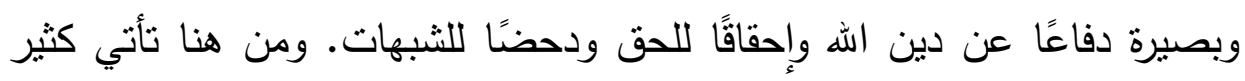

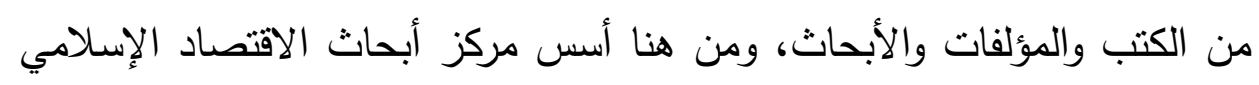

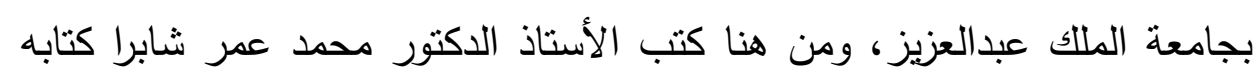
الإبداعي المتميز " الإسلام والتحدي الاقتصادي". 
إن هذا كله يعيدنا إلى أصل الموضوع الذي سنعرضه اليوم، وهو تميز الاقتصادي الإسلامي بأنه قائم على التوجيه والتشريع، وبأنه يجمع بينهما في تذاخل وتكامل متتاغمين، في حين أن كثيرًا من النظم والمذاهب الاقتصادية تشكو من الانفصال النكد بين التشريع والتوجيه وبين الأخلاق والقانون، وبين الدوافع العقدية والأخلاقية والإنسانية من طرف والواقع المالي والاقتصادي المادي الجشع القائم على ولى ولين غرائز الاسنثئار والحرص والطمع والربح الفاحش. فما هي خصائص الاقتصاد الإسلامي التي تميز بها عن كثير من المذاهب والأنظمة الاقتصادية المنتشرة في العالم.

\section{r ) خصائص النظام الإسلامي في مجال الاقتصاد}

كتب أستاذنا العلامة الثيخ محمد المبارك، رحمه الله تعالى، في آخر كتابه عن النظام الاقتصادي في الإسلام: مبادئ وقواعد عامة وتحت عنوان "خصائص النظام الإسلامي في مجال الاقتصاد" ما يلي:

ا ـبناء النظام على أسس اعتقادية قائمة على تصور عام للوجود والإنسان، وما يتولد عن هذه الأسس من دوافع إيمانية نفسية تدعم النظام وتؤيده وتساعد على تتفيذه.

r. استهدافه لأهداف أخلاقية بدلاً من هدف الإنتاج والربح المادي، وجعل الدوافع الأخلاقية والإنسانية محركات للنظام، ونوليد شعور ديني وأخلاقي يساعد على حسن تتفيذ النظام.

r.بناء النظام على تشريع مبني على قواعد كلية وأهداف اجتماعية واضحة، ومقترن بتأييد السلطة بالإضافة إلى وازع الضمير والدين. ع.بناء هذا التشريع على أساس العدالة وتكافؤ الفرص وعلى أساس التعاون

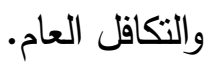


ه.بناؤه على أساس التوازن بين حرية الفرد ومصلحة المجتمع، وجمعُه بالتالي بين حرية الفرد وتذخل الدولة إقرارًا للعدالة والتكافل ومنعاُ للظلم والاستغلال.

7 ـ تميز هذا التشربع بمفاهيم خاصة للملكية والعمل تجعله مستقلاً ومتميزًا

من سائر الأنظمة الأخرى، جامعًا بين مزاياها مبرًّا من نقائصها وعيوبها. V. بناؤه على أساس التعاون والتوازن والتكافؤ (وهما غير المساواة) بدلاً من التنافس والصراع، وذلك نتيجة تطبيق قواعده التتريعية وانعكاسًا لمفاهيمه العقائدية والأخلاقية.

^. اتصاف هذا التشريع بثبات الاتجاهات والأسس ومرونة الأساليب وقابليتها للتبديل بحسب الأطوار والملابسات. (انظر الكتاب، ص ص: OV ION I ). إن ما ينبغي أن نتوقف عنده هنا من هذه الخصائص هي الخصائص الثلاث الأولى التي تتعلق بالأساس الإيماني العقائدي للاقتصاد الإسلامي وما يولده في نفس الإنسان المؤمن من دوافع إيمانية نفسية تدعم النظام وتؤيده وتساعده على تتفيذه، والتي تؤكد على الأهداف الأخلاقية للنظام الإسلامي بدلاً من أهداف الإنتاج المادي والجشع والاستئثار والربح المادي، وجعل الدوافع الأخلاقية والإنسانية محركات للنظام وأحكامه وتوليد شعور ديني وأخلاقي يساعد على حسن تتفيذ النظام. ولابد من التوقف أيضًا عند الخصيصة الثالثة المهمة، وهي أن النظام الاقتصادي الإسلامي مبني على قواعد كلية وأهداف اجتماعية واضحة، وأنه مقترن بتأييد السلطة ومؤسساتها بالإضافة إلى وازع الضمير والدين. ومن هنا يأتي عنوان هذا الحديث عن: الاقتصاد الإسلامي بين التوجيه والتشريع. ولكن ما هو مفهومنا عن الاقتصاد الإسلامي: 


\section{r) مفهومنا عن الاقتصاد الإستلامي}

إن الاقتصاد الإسلامي في مفهومنا هو "مجموعة المبادئ والأهداف والأحكام التشريعية والتوجيهات الأخلاقية التي جاء بها الإسلام في القرآن والسنة ثم اجتهادات علمائنا الكبار، بناء عليها، في موضوعات الاقتصاد والمعاملات المالية وكبريات مسائلها ومشكلاتها"، وقد يقرب ذلك مما يسمى بالمذهب الاقتصادي أو بالنظرية الاقتصادية. وإذا كان الإسلام قد بنى مذهبه الاقتصادي على أساس من الإيمان باله تعالى والمسؤولية أمامه ومن العبادة والتعاليم الأخلاقية فليس معنى ذلك أنه لم يأت بتتظيم اقتصادي وتتربع اقتصادي اجتماعي بطبق بقوة السلطة ورعاية أولي الأمر في المجتمع، فقد انتهى ذلك الوقت الذي كان يقال فيه بأنه ليس هنالك نظام اقتصادي إسلامي أو مذهب اقتصادي إسلامي، وإنما هي مجموعة من الآداب والمواعظ والتوجيهات الأخلاقية ليس إلا، بمعنى أن الإسـام ليس سوى واعظٍ مؤدب وليس حاكمًا منظمًا، فالواقع أن الثربعة عالجت كلا المجالين: مجال التربية والقيم الأخلاقية بوصفها دينًا وعبادةً وأخلاقًا، ومجال التظظيم الاجتماعي والاقتصادي بوصفها نظامًا وشربعة واجبة الطاعة والتطبيق! واستغلال الجانب الأخلاقي في الإسلام، والاتكاء عليه لطمس معالم التظيم الاجتماعي والتتربع المدني فيه غمط للحق وميل عن الأمانة العلمية والمنهجية!

على أننا إذا كنا نؤكد على أن للإسلام نظامه الاقتصادي ومذهبه الاقتصادي وتتربعاته المالية مع اقتران ذلك بالتوجيه الأخلاقي والقاعدة الإيمانية، فليس معنى ذلك أننا نقول بوجود (علم اقتصاد) في الإسلام. فهناك فرق كبير بين المذهب الاقتصادي والتشريع الاقتصادي، وبين علم الاقتصاد باعتباره علمًا وضعيًا تحليليًا جديدًا، ولست أنا الذي يتكلم أمامكم عن الفرق بين المذهب الاقتصادي وعلم الاقتصاد. والإسلام بوصفه دينًا ونتربعًا ربانيًا ليس من وظيفته 
أن يضع علمًا في الاقتصاد، كما ليس من وظيفته ولا من مهمته أن يضع علما

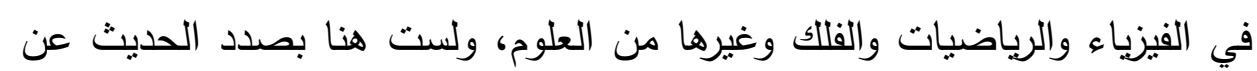

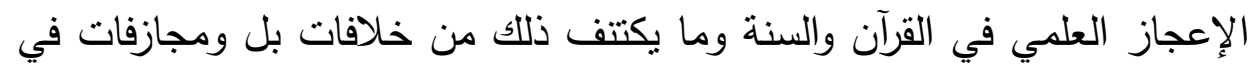
بعض الأحيان، ولم نتفق بعد على وجود إعجاز علمي اقتصادي في القرآن، والحديث ذو شجون!

والمهم هو أن نقرر أن الاقتصاد الإسلامي ليس علمًا اقتصاديًا، بل هو

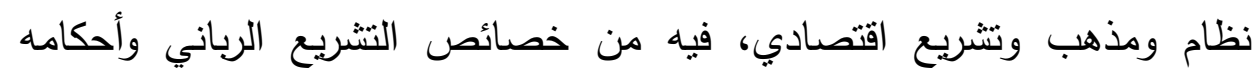

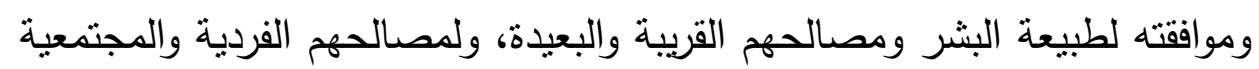
والدنيوية والأخروية، ما يجعله جديرًا بالإعجاب والتقدير والإتباع.

إن الاقتصاد الإسلامي بهذا المعنى هو أحكام تثريعية ملزمة في أكثر

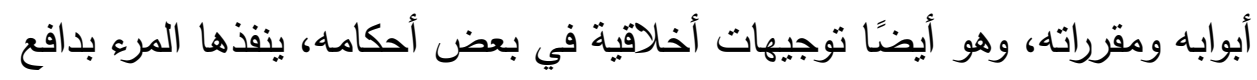
إيمانه وعقيدته، دون تدخل سلطة الدولة الخارجية، ولكنه في كلتا الحالتين يقوم على أساس ديني وأخلاقي من الإيمان باله وطاعته وخشيته ومراقبته وابتغاء

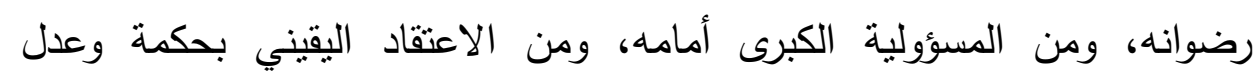

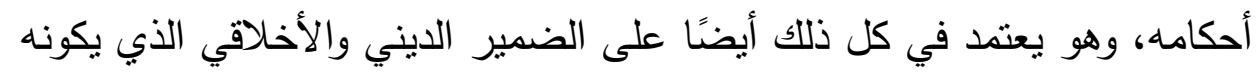

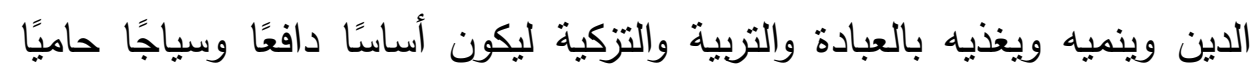
لأحكامه التشريعية الملزمة وأحكامه التشريعية النطوعية.

\section{؛) الطابع الإيماني التعبدي التوجيهي للاقتصاد الإسلامي}

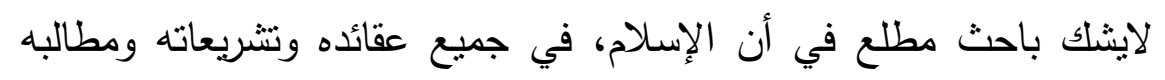

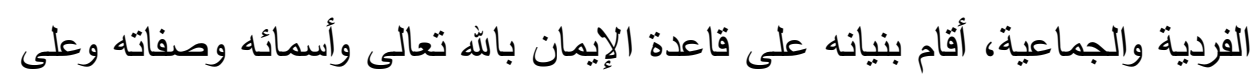

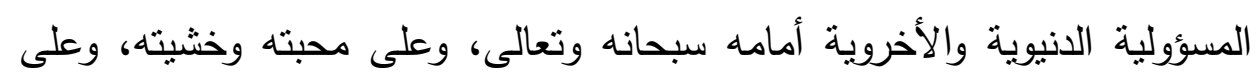

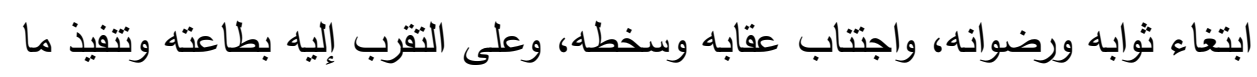

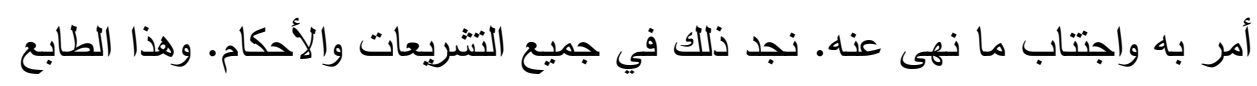


الإيماني التعبدي التوجيهي يشمل جميع جوانب الإنسان وتصرفاته، ويشمل حياته الخاصة وحياته العامة، ويشمل الأسرة والجيران والمجتمع، ويشمل التشربعات المتعلقة بالزواج والطلاق وبر الوالدين، ويشمل التشربعات المتعلقة بالأنفس والقصاص والحدود، ويشمل التشريعات المتعلقة بالأموال والعقود والتجارات والبيوع باته والإقراض والديون، ويشمل شؤون الدنيا وشؤون الآخرة، بل يشمل الإنسان والحيوان والزرع والماء، ويشمل كل شيء: "إن الله كتب الإحسان على كل شيء، فإذا قتلتم فأحسنوا القتلة، وإذا ذبحتم فأحسنوا الذبحة وليحد أحدكم شفرته وليرح ذبيحته". ثم إن التشريعات الاقتصادية والأحكام الاقتصادية لا تشذ عن هذه القاعدة. فهي كلها تقع ضمن الدائرة الإيمانية التعبدية التوجيهية الأخلاقية، بمعنى أن الالتزام بها وفعلها يستتد إلى الإيمان بالله، ويعتبر عبادة لله وتقربًا إليه سبحانه، وهذا فحوى شمولية مفهوم العبادة في الإسلام.

ثم إن الاقتصاد الإسلامي ليس مجرد الأحكام النشريعية الملزمة من قبل السلطة ومؤسساتها، أو من قبل النظام القضائي، بل هنالك إلى جانب ذلك الأحكام المستحبة، غير الإلزامية من قبل السلطة، وهنالك مندوبات دينية وتوجيهات أخلاقية ليس لها صفة الإلزام الخارجي السلطوي، ولكن لها أثرها في النظام الاقتصادي في جملته باعتبارها عاملاً مؤثرًا من عوامل فعاليته ونجاحه في تحقيق أهدافه ومقاصده.

فالنهي عن الاكتتاز في قوله تعالى: "والذين يكنزون الذهب والفضة ولا ينفقونها في سبيل الهه فبشرهم بعذاب أليم" الآية و- سورة التوبة، يعتبر أمرًا توجيهيًا ودينيًا غير ملزم من الناحية التشريعية والقضائية، ولكنه عامل مؤثز في تتشيط الحركة الاقتصادية ودوران المال والخروج من الركود الاقتصادي، بل إن اكتتاز المال وتجميده يعتبر ظاهرة من ظواهر المجتمعات الراكدة والمتخلفة اقتصاديًا. 
والنهي عن الإسراف والتبذير وعن البخل والتقتير قد ورد في القرآن والسنة في كثير من المواطن، وهو من باب النصائح والتوجيهات الأخلاقية، ويكاد يكون أمرًا بين العبد وربه، فيكون من باب التدين الفردي، وليس من باب الأوامر دهر باب

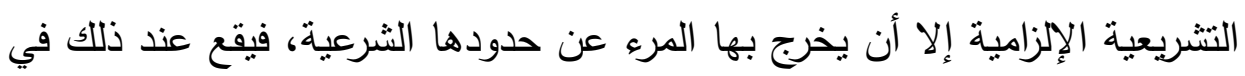
فعل المحرمات أو الإخلال بالواجبات الأسرية والاجتماعية (وهو ما يسمى لهاء بالسفه). ولاشك أن هذا النهي بطرفيه له علاقة وثثقة بأهداف النظام الاقتصادي وحيويته، فالتبذير هو نوع من إضاعة المال ووضع الثروة والإنتاج في غير محله، وتجاوز حدود الرشد الاقتصادي، والتقتير هو نوع من توقيف حركة الاستهلاك المؤدية لتنشيط الإنتاج ونموه. وكل هذا من باب التوجيه والواجبات الديانية الأخلاقية في الأصل، وإن كان بعض العلماء يرون أن لولي الأمر أن يجولها من مستوى التوجيهات الدينية والأخلاقية إلى مستوى القواعد والتنظيمات التشريعية الملزمة بقوة السلطة التتفيذية إذا اقتضت المصلحة ذلك! قالوا:

(وإذا كان لولي الأمر الحق في أن يوجب مباحًا أو يحرمه في أوقات وظروف معينة لمصلحة عامة راجحة، فإن حقه هنا قائم من باب أولى، لوجود أوامر وتوجيهات إلهية في الأصل تتهى عن هذه التصرفات )). إن الأصل العقائدي الذي يكمن وراء كل مقررات الاقتصاد الإسلامي من تشربعات وتوجيهات، وما يتبع ذلك الأصل العقائدي من مسؤولية تعبدية وأخلاقية ومن رغبة في ثواب الطاعة والالتزام وخشية من عقاب المخالفة والعصيان، إن ذلك كله هو ما يميز الاقتصاد الإسلامي عن غيره من المذاهب والنظم الاقتصادية 
وقد عنيت الثريعة عناية خاصة بتربية الضمير الفردي وتغذيته بمعاني محبة الله ورجائه والخوف منه وخثيته، حتى يكون الفرد أكثر استعدادًا وإقبالاً على بلى بترئه تلبية وتتفيذ الثريعات والتوجيهات والأوامر والنواهي، ولو لم تكن هنالك رقابة خارجية أو إلزام خارجي. ولذلك نرى أن التوجيه الديني والأخلاقي الذي يقوي الوازع الإيجابي للعمل والإنتاج والبعد عن المناهي والمخالفات يصاحب كل التشريعات والأحكام القضائية الإلزامية.. ففي الإسلام: كل ما كان فيه تشريع إلزامي فإن فيه توجيهًا خلقيًا وإيمانيًا في الأصل، فالتوجيه والترغيب والترهيب هي الإنيا الأصل في جميع الأوامر والتكليفات.

ويمكننا أن نقول: إن كل تشريع وراءه توجيه، وليس كل توجيه يفضي بالضرورة إلى تشريع. فكل تشريع توجيه وليس كل توجيه تشريعًا، إلا إذا فهمنا

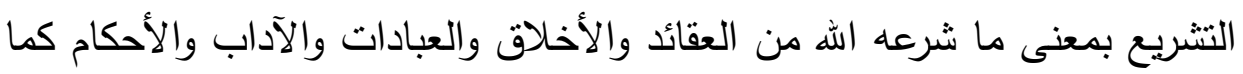
جاء في قوله تعالى: "شرع لكم من الدين ما وصىى به نوحًا والذي أوحينا إليك وما

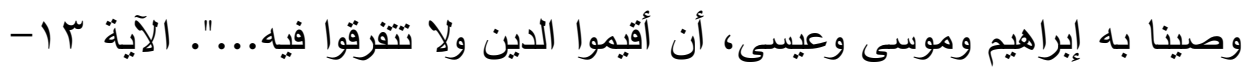
سورة الشورى.

فالتشريع لا ينفك عن التوجيه والتعبد في الإسلام، ولكن التوجيه قد ينفك عن الإجبار الخارجي وعن التشريع الملزم بقوة السلطان. فتحريم الربا والمعاملات الربوية وما يقاربها: تشريع وتوجيه. وتحريم القمار والمعاملات المحفوفة بالغرر الكبير : تشريع وتوجيه. وتحريم الغش والاحتكار والنجش وإخفاء العيوب وأكل أموال الناس بالباطل هي تشريع وتوجيه. ووجوب الزكاة وأداؤها، ووجوب النفقة على الأقارب المستحقين، والوفاء بالعقود والالنزامات هي تشريع وتوجيه تعبدي وأخلاقي في آن. 
والصدقات النطوعية بأنواعها المختلفة هي توجيه، وليست تشربعًا

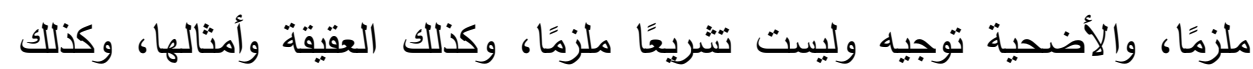

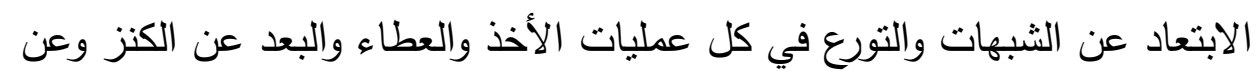
التدليس والأيمان الكاذبة وعن الغبن اليسير والغرر اليسير: هذه كلها من باب التوجيه الديني والأخلاقي وليست من باب التشريع الملزم.

وهكذا يتبين لنا أن الثريعة بشكل عام، وفي ما نسميه اليوم بالاقتصاد الإسلامي بشكل خاص، قد اعتمدت على الجمع بين التوجيه والتشربع، فلم تهمل جانب التوجيه في أي تصرف من التصرفات وفي أي حكم من الأحكام، ولكنها في نفس الوقت لم تعتمد كليًا عليه بل كملت دوره، في بعض الجوانب، بالتشربع الذي يرعاه المجتمع وتحميه مؤسسات الدولة وأجهزتها الرقابية والقضائية والتتفيذية. وتتجلى مزاوجة الثريعة بين التوجيه والتشريع في أنها توجه الضمير نحو قيم العدل والأمانة في معاملة الناس وحب الخير لهم وإنصافهم من النفس وعدم ظلمهم وعدم أكل أموالهم بالباطل، وتدعو هذا الضمير إلى ترك الغش والخلابة والخيانة والتغرير ، وهي في الوقت نفسه وضعت تشريعات إلزامية محددة وحرمت أنواعًا من المعاملات تتضمن الظلم والاستغلال وأكل أموال الناس بالباطل كالربا والغش والاحتكار، وشرعت الضمانات القانونية لتحقيق العدل ومنع الظلم ودرء الاستغلال في كتابة الدين وتوثيق العقود وتتفيذها بقوة السلطان وحراسة مؤسسات المجتمع التنفيذية.

على أننا يجب أن نؤكد هنا بأن الأصل هو الحكم الديني والأخلاقي وأن الحكم القضائي الإلزامي يأتي تبعًا ولاحقًا، ومن هنا ذكر فقهاؤنا أن هناك أحكامًا ديانية وأحكامًا قضائية، فالأحكام الديانية هي التي تتفق مع الواقع ومع المعتقد الداخلي لكل فرد طبقًا لتعاليم الثربعة، والأحكام القضائية هي التي يحكم بها 
القاضي وتتفذها مؤسسات الدولة بناء على الأدلة الظاهرة التي قد تكون غير مطابقة للواقع الحقيقي، ولكن حكم القاضي هنا لا يحل حرامًا ولا يحرم حلالاً، وتبقى الرقابية الذاتية الدينية والأخلاقية هي الأساس، كما جاء في الحديث المروي عن أم المؤمنين أم سلمة رضي الله تعالى عنها، وهو عند البخاري:

"إنكم لتختصمون إلي، ولعل بعضكم أن يكون ألحن بحجته من بعض، فأقضي له على نحو ما أسمع، فمن قضيت له من حق أخيه شيئًا فلا يأخذه فإنما أقطع له له قطعة من النار".

ولاشك أن الحكم الدياني بالنسبة للمسلم هو الحكم الذي ينسجم مع دينه وقيمه وراحة ضميره وطمأنينة نفسية في دنياه وأخراه، وهو ما بعتبر عاملاً كبيرًا من عوامل نجاح النظام الاقتصادي في الإسلام وفعاليته.

\section{•) الطابع التشريعي القضائي الإلزامي للاقتصاد الإسلامي}

إن كل ما ذكرناه سابقًا يؤكد على الطابع الإيماني التوجيهي الأخلاقي للاقتصاد الإسلامي وهو ما يميزه عن غيره من الاقتصادات الرأسمالية والليبيرالية والاشتراكية وغيرها، سواء في منطلقاته وأسسه أو في غاياته وأهدافه أو في أحكامه وتتربعاته، والأوضاع الاقتصادية اليوم والباحثون الاقتصاديون النزبهون اليوم يثددون على أخطار غياب الطابع الأخلاقي والإنساني في الاقتصاديات المعاصرة، وأنه يغلب عليها اليوم نزعة الإنتاج المادي والاستكثار الربحي والجثع الثع الحي الرأسمالي بعيدًا عن القيم الأخلاقية لا في الإنتاج ولا في الأجور ولا في الأهداف

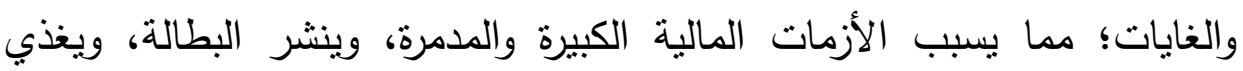
الجريمة، ويفاقم من التفاوت الطبقي، ويؤدي إلى الفساد وتتمية الغرائز البهيمية 
لكن هذا الطابع الإيماني التوجيهي العام للاقتصاد الإسلامي ينبغي أن لا يحجب عنا طابعه التشربعي الإلزامي، فإلى جانب التوجيهات الإيمانية والأخلاقية هنالك الرقابة التشريعية والقضائية الإلزامية، وإلى جانب الدوافع الإيمانية والأخلاقية النبيلة هناك سلطة الدولة وحراسة أجهزتها الرقابية والتتفيذية.

والحقيقة أن الاقتصاد الإسلامي هو اقتصاد تشريعات وأحكام ملزمة وليس مجرد توجيهات أخلاقية ومواعظ ومشاعر وجدانية متروكة لضمير كل فرد، كما يحلو أن يقول ذلك بعض جهلة المتتطعين.

وشأنه في ذلك شأن جميع جوانب الثريعة الإسلامية الأخرى:

- فقاعدة الوفاء بالعقود قاعدة تشريعية ملزمة" يا أيها الذين أمنوا أوفوا بالعقود".

وإذا كان الخطاب موجهًا للمؤمنين فليس معنى ذلك أنهم غير ملزمين بذلك قضائًاً وبسلطة الحكام وأولياء الأمور ، بل النص على ذلك يستلزم التتفيذ بسلطة

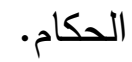

身

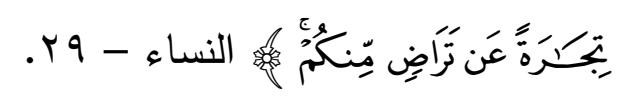

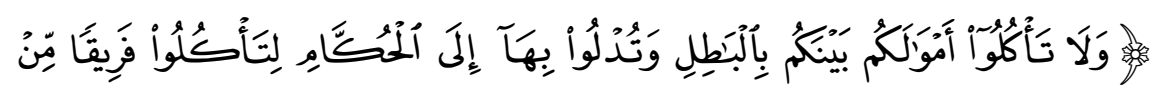

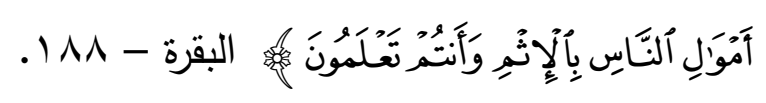

- والربا محرم وممنوع في الإسلام ديانة وقضاء، وبسلطة الحكام. وغير ذلك من أحكام ومفردات الاقتصاد الإسلامي، فهي في أكثرها أحكام تشريعية ملزمة يحكم بها القضاء وتتفذها أجهزة الدولة وتحميها. بل إن وظيفة الحاكم أو الإمام في الإسلام هي "حراسة الدين وسياسة الدنيا به"، و "يزع الله بالسلطان ما لايزع 
ولعل أوضح وأبين ما يذكر في تأكيد الطابع التشريعي الإلزامي للاقتصاد

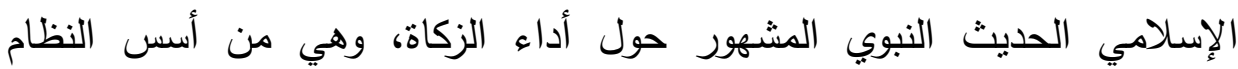

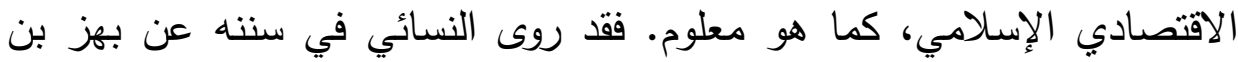
حكيم عن أبيه عن جده قال: سمعت النبي صلى الإنه عليه وسلم يقول: " في كل إبل سائمة: في كل أربعين ابنة لبون، لايفرق إبل عن حسابها، من

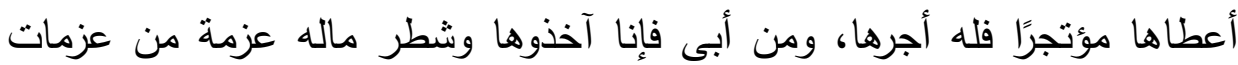

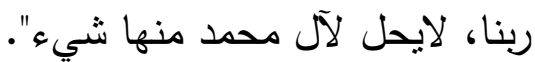

قال الثافعي في القديم: من منع زكاة ماله أُخذت، وأُخذ شطر ماله عقوبة الثة على منعه، واستخل بهذا الحديث.

ثم قال في الجديد: لايؤخذ إلا الزكاة لاغير، وجعل هذا الحديث منسوخًا، وقال: "كان ذلك حيث كانت العقبات في المال ثم نُشت". وهنالك خلاف بين الفقهاء في عقوبة مانع الزكاة بأخذ شطر من ماله، وخلاف في تقسير كلمة الثطر هنا.

على أن هناك تتظيمًا إسلاميًا اقتصاديًا آخر غير إلزامي، بل يستمد قوته من

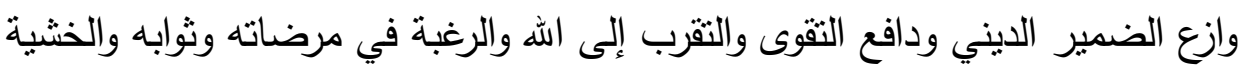

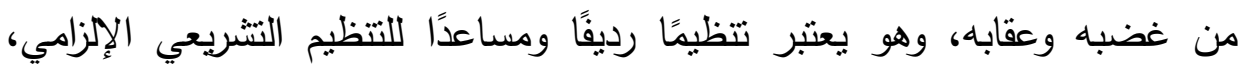

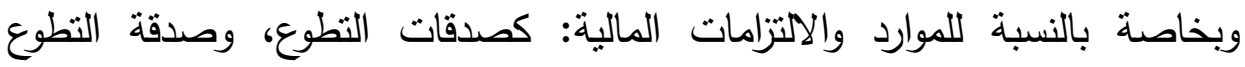

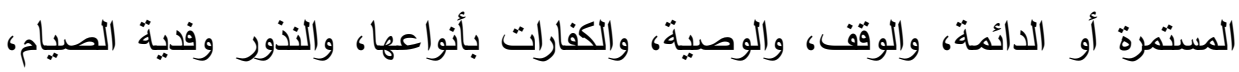
وفدية المضطر لحلق رأسه أثثاء إحرامه بالحج وغيرها..

وينبغي أن لا ننسى هنا أن هذا الطابع التشريعي الإلزامي في أحكام الاقتصاد الإسلامي بستبطن الأخلاق الفاضلة والغايات النبيلة من احترام الحقوق والقيام بالالتزامات، ومن العدل والإنصاف والتكافؤ ومن النهي عن الجشع والغش والتحايل

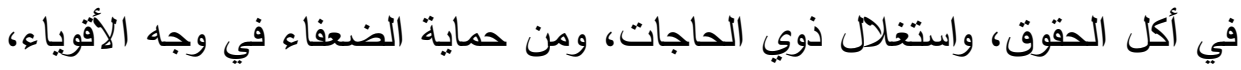

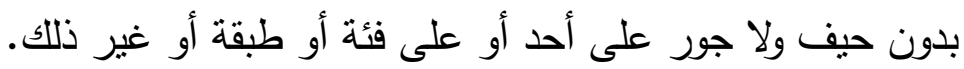


؟) الطابع التشريعي والطابع التوجيهي بين التذاخل والتكامل

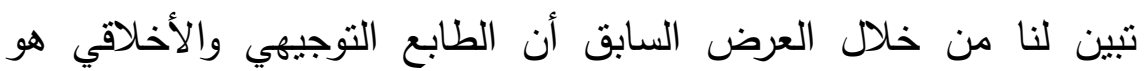

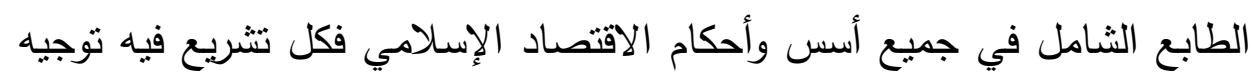
وأساس أخلاقي وهدف أخلاقي، وليس كل توجيه نتريعًا إلزاميًا.

فهناك عموم وخصوص مطلق بينهما، وهناك تداخل بينهما أيضًا؛ لأن

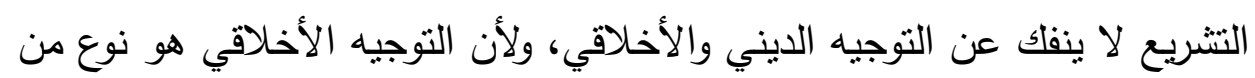

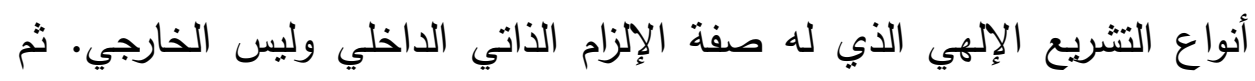

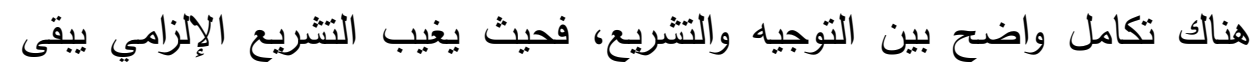

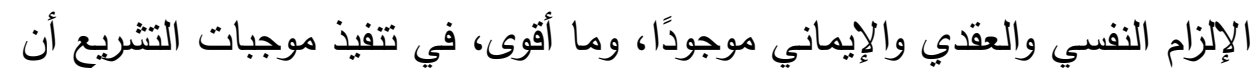

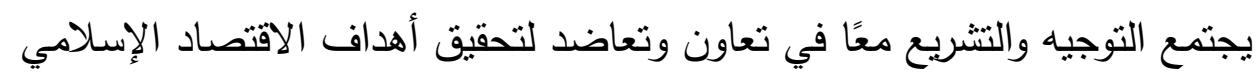
وغاياته المنلى!

) خاتمة ( V

في خاتمة هذه المحادثة والمداخلة يبدو لي أن هناك إثكاليتين مهمتين متصلتين بهذا الموضوع:

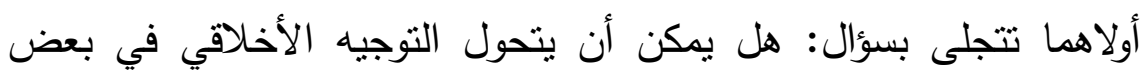

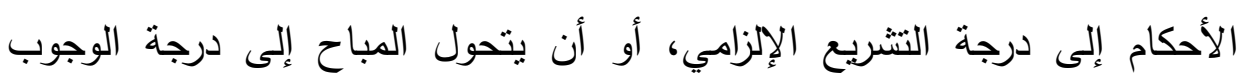

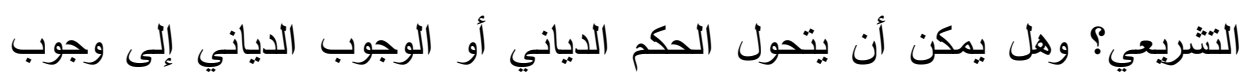
تشريعي ملزم وقضائي؟ وهن

وثانيتهما تقول: هل الاقتصاد الإسلامي قابل للنطبيق في مجتمع غير ألنادي

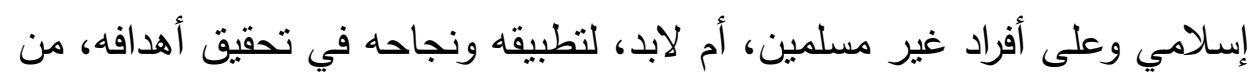

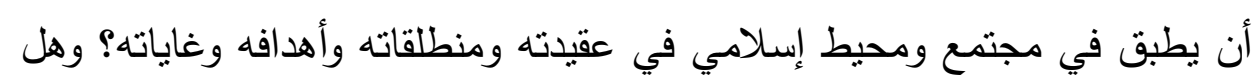

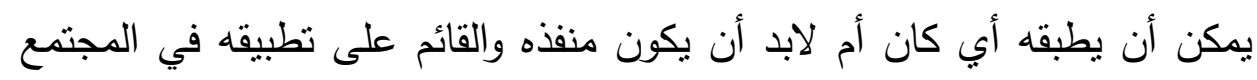

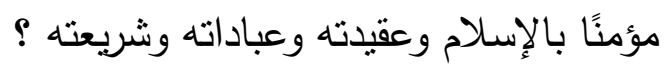


أتزرك الإجابة على هذين التساؤلين للحوار والمناقتشة، أو للبحث لاحقًا، وأختم حديثي بهذا الاقتباس من كتاب الباحث الفرنسي "جاك أوستروي" "الإسلام والتتمية الاقتصادية" حيث يقول:

" الإسلام هو نظام الحياة النطبيقية والأخلاق المثالية الرفيعة معًا، وهاتان

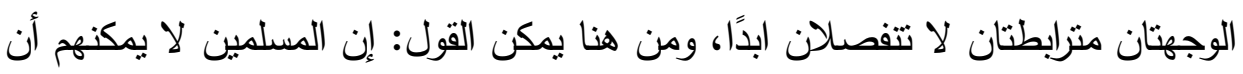

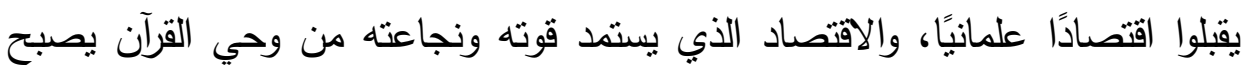
بالضرورة اقتصادًا أخلاقيًًا".

وصدق اله العظيم إذ يقول:

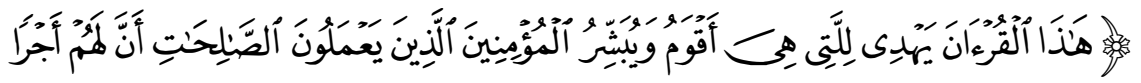

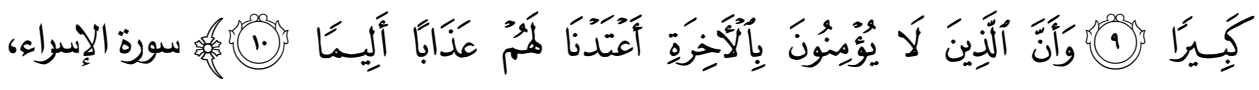
الآيتان 9-1. 


\title{
Islamic Economics between Directives and Legislation
}

\author{
Abdullatif Al-Sabbagh \\ Faculty of Arts \& Humanities \\ King Abdulaziz University, Jeddah, Saudi Arabia
}

Abstract. This dialogue shows the most important characteristics of economic system in Islam with special focus on integration between religious instructions, moral guidance, and mandatory legislation. Islamic Economics is based on faith and ideological perspectives with moral, psychological, and devotional objectives. This is meant to keep away excessive materialism (desire) and exploitation, which leads to crises and bottlenecks faced by (materialistic) economic system.

Researchers have distinguished between Economic Doctrine and Economics (science). According to them Islamic economics is integrated economic doctrine and not economics (science).

The researchers stressed that in Islamic economic system the legislation is compulsory and not mere guidance, sermons or moral/ethical teaching, which forms the central point of Islamic economic system.

The researcher explained that there are differences and compatibility issues between the directives of the Islamic economics and the legislation. Although the directives are not always binding and legislated by the state.

In the end, he was exploring the possibility of transferring some economic provisions of the individual guideline to compulsory legislative level, if this was in public interest. He, wondered the applicability of Islamic economics in NonIslamic (Non-Muslim) society (nation) ?! 